\title{
Migrant and ethnic minority status as risk indicators for schizophrenia
}

Citation for published version (APA):

van der Ven, E., \& Selten, J-P. (2018). Migrant and ethnic minority status as risk indicators for schizophrenia: new findings. Current Opinion in Psychiatry, 31(3), 231-236.

https://doi.org/10.1097/YCO.0000000000000405

Document status and date:

Published: 01/05/2018

DOI:

10.1097/YCO.0000000000000405

Document Version:

Publisher's PDF, also known as Version of record

Document license:

Taverne

\section{Please check the document version of this publication:}

- A submitted manuscript is the version of the article upon submission and before peer-review. There can be important differences between the submitted version and the official published version of record.

People interested in the research are advised to contact the author for the final version of the publication, or visit the DOI to the publisher's website.

- The final author version and the galley proof are versions of the publication after peer review.

- The final published version features the final layout of the paper including the volume, issue and page numbers.

Link to publication

\footnotetext{
General rights rights.

- You may freely distribute the URL identifying the publication in the public portal. please follow below link for the End User Agreement:

www.umlib.nl/taverne-license

Take down policy

If you believe that this document breaches copyright please contact us at:

repository@maastrichtuniversity.nl

providing details and we will investigate your claim.
}

Copyright and moral rights for the publications made accessible in the public portal are retained by the authors and/or other copyright owners and it is a condition of accessing publications that users recognise and abide by the legal requirements associated with these

- Users may download and print one copy of any publication from the public portal for the purpose of private study or research.

- You may not further distribute the material or use it for any profit-making activity or commercial gain

If the publication is distributed under the terms of Article $25 \mathrm{fa}$ of the Dutch Copyright Act, indicated by the "Taverne" license above, 


\title{
Migrant and ethnic minority status as risk indicators for schizophrenia: new findings
}

\author{
Els van der Ven ${ }^{\mathrm{a}, \mathrm{b}}$ and Jean-Paul Selten ${ }^{\mathrm{a}, \mathrm{b}}$
}

\begin{abstract}
Purpose of review
Arguably, the strongest evidence of an environmental contribution to the cause of psychosis is the increased risk for certain groups of migrants and ethnic minorities. This article summarizes findings published since 2016.
\end{abstract}

\section{Recent findings}

Two studies suggested that migration or minority status are proxies for exposure to an inferior social status. A study from Bologna, Italy, showed that the psychosis risk for internal migrants from Southern Italy was as much increased as that for international migrants. A report from New Zealand reported a higher risk for Maoris than for the remainder of the population.

Furthermore, a Danish investigation showed that own-group ethnic density of the neighbourhood at age 15 strongly modified the psychosis risk at adult age. This rules out differential mobility during the prodromal phase as an explanation for the ethnic density effect. Preliminary evidence suggests that the psychotogenic effect of migration may be mediated by elevated dopamine in the striatum.

\section{Summary promising avenue for research into pathogenesis. \\ Keywords \\ dopamine, ethnicity, migration, schizophrenia, social exclusion}

An increasing body of evidence suggests that the higher psychosis risk for certain migrant or ethnic minority groups is due to an inferior social status. Neuroimaging of the dopamine system appears to be a

\section{INTRODUCTION}

Previous work has demonstrated an increased risk of nonaffective psychotic disorder (NAPD) for migrants and their children, with pooled risk ratios of 2.3 [95\% confidence interval (95\% CI) 2.0-2.7] for first and 2.1 (95\% CI 1.8-2.5) for second-generation immigrants [1]. There is also evidence of an increased risk for certain ethnic minorities. Bresnahan et al. [2], for example, reported an increased risk for African-Americans. The aim of this review is to provide an update of relevant epidemiological, biological and experimental findings published in 2016 and 2017. It concerns migrants and their children, as well as members of ethnic minority groups without a migration history who share with migrants the experience of minority-related stress.

\section{IS THE INCREASED PSYCHOSIS RISK IN IMIMIGRANTS A TRUE FINDING?}

Sampling and diagnostic bias have been suggested to (partially) account for findings supporting the association between migrant status and risk for NAPD.

\section{Sampling bias}

Hogerzeil et al. $\left[3^{*}, 4\right]$ compared two methodologies for including new psychosis cases in incidence studies, the first-contact and the longitudinal registermethod. This was possible in the city of the Hague where a first-contact incidence study was conducted, while at the same time a psychiatric register was operational. Because the first-contact approach had a tendency to miss older Dutch patients who

\footnotetext{
${ }^{a}$ Maastricht University, School for Mental Health and Neuroscience, Maastricht and ${ }^{\mathrm{b}}$ Rivierduinen Mental Health Institute, Leiden, The Netherlands

Correspondence to Jean-Paul Selten, Rivierduinen Mental Health Institute, GGZ Leiden, Sandifortdreef 19, 2333 ZZ Leiden, the Netherlands. E-mail: j.selten@rivierduinen.nl
}

Curr Opin Psychiatry 2018, 31:231-236

DOI:10.1097/YCO.0000000000000405 


\section{KEY POINTS}

- The increased incidence of NAPD in certain migrant and ethnic minority groups appears to be a true finding that cannot be explained in terms of diagnostic or sampling bias.

- This increased risk also applies to internal migrants and ethnic minorities without migration history, emphasizing the role of outsider position in psychosis aetiology.

- Living in a high own-group ethnic density area during puberty protects against the onset of psychosis in later life.

- Preliminary evidence shows that the association between migrant status and risk of NAPD may be mediated by elevated dopamine in the striatal regions.

were treated for another disorder before the onset of psychosis, the longitudinal psychiatric register method resulted in a significantly higher incidence in this group [4]. On the basis of register data, the incidence of schizophrenia among immigrant groups was still significantly increased [relative risk $(\mathrm{RR})=1.7 ; 95 \%$ CI 1.3-2.2], but less increased than when based on the first-contact method $(\mathrm{RR}=1.9$; 95\% CI 1.2-3.3) [3"].

Although these findings are of interest, it is worthwhile to note that many registry studies from Sweden, Denmark and the Netherlands counted new cases of psychotic disorder, regardless of previous contacts for other disorders, and reported consistently increased psychosis incidence rates for migrants from developing countries [5-7].

Sampling bias may also arise when incident cases are not treated in the regular mental healthcare system and not included in incidence studies. A systematic review reported consistently higher prevalence rates of psychotic disorder among black migrant and ethnic minority detainees in different parts of the world, including Australia, Western Europe and the USA [8].

In conclusion, sampling bias is probably present in most studies and may augment or attenuate the true relative risk of psychotic disorder in migrant and ethnic minority groups. Although its influence is unlikely to change overall conclusions, efforts should be made to minimize sampling bias.

\section{Diagnostic bias}

Zandi et al. [9] interviewed native Dutch and Moroccan-Dutch patients twice: using a standard version and a culturally sensitive version of the Comprehensive Assessment of Symptoms and History
(CASH and CASH-CS, respectively) [10,11]. Using the standard version, they found a tendency towards overdetection of delusions and underdetection of mania in Moroccan-Dutch patients.

Using another outcome than diagnostic categories, Termorshuizen et al. [12"] examined dispensing rates of antipsychotic medication by ethnicity in the four largest Dutch cities. Adjusted for age, sex, socioeconomic status (SES) and household composition, the RR for incident dispensing of antipsychotics among the Turkish and Moroccan-Dutch was 2.1 (95\% CI 1.9-2.3) and 2.1 (95\% CI 1.9-2.4) respectively. Remarkably, incident and prevalent dispensing of antipsychotics was not increased among Surinamese and Antillean-Dutch individuals, for whom an increased incidence of psychotic disorder has been reported $[13,14]$. This may be explained by undertreatment or a decreasing incidence over time, due to successful integration [12"]. It is important to mention, however, that dispensing of antipsychotic medication does not equal the prevalence or incidence of psychotic disorder, because this medication is also prescribed to individuals with other diagnoses.

Pignon et al. [15] conducted a survey in a large sample of the French population. They reported a significantly increased prevalence of both psychotic disorder, and subclinical psychotic symptoms in first, second and third-generation migrants, which supports the influence of migrant position along the psychosis continuum [16].

It has been suggested that an excess of brief, reactive psychoses causes a high incidence in Black minorities [17]. Consequently, the results of a 10year follow-up study in the UK are of great interest. AESOP-10 concerns 532 individuals who initially presented with a first-episode psychosis (FEP) in three relatively deprived and ethnically diverse catchment areas in south-east London and Nottingham [18"']. Compared with White British patients, the trajectory of psychosis in Black Caribbean patients showed a more continuous course of illness and lower rates of recovery. Both Black Caribbean and Black African patients had worse social functioning and service use outcomes through their course of illness, including a higher likelihood of compulsory admission and police involvement. Intriguingly, the difference seemed to increase after more years of follow-up, which may explain why some previous short-term follow-up studies failed to detect this [18"-]. For example, the GAP-5 study reports on the 5-year outcome of 245 FEP patients of the same ethnic groups in South London using electronic psychiatric clinical notes [19]. They found similar ethnic disparities in service use outcomes, that is, more compulsion and longer hospital 
admissions in Black African and Black Caribbean patients, but no ethnic differences in functional disability, recovery rates or illness severity during the follow-up period. Importantly, neither study provides evidence for a more benign course of illness among Black minorities in the UK.

\section{IS THE INCREASED RISK FOR \\ NONAFFECTIVE PSYCHOTIC DISORDER AMONG IMIMIGRANTS A SPECIFIC FINDING?}

A meta-analysis of the incidence studies of mood disorders in first and second-generation immigrants obtained a slightly increased risk in the first, not the second generation ( $\mathrm{RR}=1.3,95 \%$ CI $1.1-1.4)$. Furthermore, there was no evidence of a significantly increased risk of bipolar affective disorder [20]. A large population survey in France observed a similar pattern: an increased lifetime prevalence for unipolar depression in immigrants $(\mathrm{RR}=1.4,95 \% \mathrm{CI}$ 1.3-1.5), not for bipolar disorder or dysthymia [21]. In sum, RRs for mood disorders are lower than those reported for NAPD.

Previous studies from the UK, however, have reported increased rates of bipolar affective disorder [22] or affective psychotic disorder [23,24] for Black minorities. One could hypothesize, therefore, that certain migrant groups are at an increased risk for mood disorders with psychotic features and not, or to a much lesser extent, for mood disorders without such features.

Furthermore, a large study examining the risk of eating disorders in immigrants to Denmark and Sweden found decreased incidence rates for anorexia and bulimia nervosa [25]. Studies investigating migrant or ethnic minority status in relation to the incidence of autism-spectrum [26] or substance use [27] disorders have produced mixed findings and are inconclusive.

Altogether, the research findings indicate a certain degree of specificity for the relationship between migrant status and risk for NAPD.

\section{The paradoxically low rates of depression in African-Americans}

Barnes and Bates [28"] conducted a systematic review of prevalence studies of major depressive disorder among African-Americans and found consistent (eight out of nine) reports of a lower prevalence of depression in African-Americans relative to the white majority group in the USA. This contrasts sharply with the increased rates of psychosis among African-Caribbeans in the UK [29] and AfricanAmericans in the USA [2]. These findings are paradoxical, because African-Americans experience more social adversity and have a lower SES. Consequently, one could hypothesize that individuals of African ancestry, when exposed to adversity, are relatively more prone to develop psychotic symptoms, while members of white ethnic groups would tend to develop mood symptoms. In other words, psychosocial stress may lead to the onset of psychiatric symptoms, the content of which may be determined to a certain degree by a genetic predisposition and/or cultural background.

\section{OTHER EPIDEMIOLOGICAL ADVANCES}

One interesting question for this research field is the putatively higher risk for refugees than for nonrefugees. As several variables related to a migrant's region of origin may influence psychosis risk $[30,31]$, it is important to distinguish between refugees and nonrefugees from the same area.

Hollander et al. [32"'] conducted the first study comparing the incidence of NAPD in political refugees granted asylum in Sweden and economic migrants from the same regions. Refugees and nonrefugees from sub-Saharan Africa had a similarly increased risk. Refugees from the other three regions, that is, the Middle East and North Africa, Asia and Eastern Europe and Russia had a higher risk for NAPD than nonrefugee migrants from these respective areas (overall $\mathrm{RR}=1.7,95 \% \mathrm{CI} 1.3-2.1$ ). This may suggest that the exposure to social adversities before migration, including war and persecution, may have an additive, 'refugee effect' on psychosis risk [32"']. Although this is a plausible explanation, the categories of region of origin in this study were very broad (e.g. 'Asia') and the comparability of a political refugee from Bangladesh to an economical migrant from Japan remains questionable.

Researchers of the SEPEA study included all incident cases of psychosis in a rural setting in the East of England where 10\% of the population is of non-British white, mostly European origin, following the EU expansion in 2004 [33"]. After controlling for possible confounders, such as SES, population density and deprivation, the risk pattern in Black African, Black Caribbean and Pakistani migrants in this rural environment resembled findings previously observed in urban environments [23,34]. Importantly, there was little evidence of an increased risk in white, non-British (mostly Eastern European) immigrants [33"].

A curious finding in the field concerns the excessive sex gap in psychosis risk among North African migrants in Europe [35]. Pooled estimates from five European incidence studies yielded male-to-female 
risk ratios of 5.1 (95\% CI 3.1-8.4) for migrants from the Maghreb compared with 1.8 (95\% CI 1.3-2.5) for native Europeans. Possible explanations for the disproportionally high rates in male immigrants from the Maghreb include achievement-expectation mismatch, social marginalization and/or excessive illicit drug use [35].

Two thought-provoking reports from Italy [36"] and New Zealand [37"] concerned internal migration and a special kind of minority status. A study from Bologna, Italy, reported a two-fold increased psychosis risk for internal migrants in comparison with native Italians from Emilia Romagna, the region surrounding Bologna [36"]. Most of these internal migrants moved from South Italy, where educational levels are lower and rates of unemployment and poverty higher [38]. The risk increase for internal migrants was as high as that for the foreignborn. A study from New Zealand reported a two-fold higher incidence of schizophrenia among the Maori than among the non-Maori. Of note, the Maori constitute the original population of New Zealand and the non-Maori are migrants or descendants of migrants [37"]. These findings are of eminent interest, because they suggest that migration or ethnic minority status are proxies for exposure to an inferior social status or discrimination.

One of the most striking findings in this research area is the protective effect of ethnic density, that is, the greater the proportion of the own ethnic group in the neighbourhood, the lower the risk for psychotic disorder. It has now been replicated in a nationwide study from Denmark [39"']. An important strength of the Danish study is the measurement of ethnic density at age 15 instead of at the time of diagnosis. This excludes the possibility that individuals with a genetic liability moved to particular neighbourhoods during the prodromal phase of the illness. Another strength of this study is that it has high external validity, because the entire population of Denmark was included [39"']. In conclusion, ethnic density, perhaps as a proxy for social cohesion, may mitigate the pathogenic effects of minority stress.

Das-Munshi et al. [40] conducted a longitudinal cohort study including more than 18000 individuals with schizophrenia, schizoaffective or bipolar affective disorder, and determined mortality rates by ethnicity. Adjusted hazard ratios indicated that Black Caribbean, Black African and South Asian ethnic minority patients had an overall lower mortality rate of at least $27 \%$ than their white British counterparts. Potentially protective factors, such as high ethnic density, social support and protective social norms deserve further investigation.

\section{ADVANCES ON UNDERLYING}

MECHANISNS

Neurobiological evidence on underlying brain mechanisms points to increased dopamine synthesis capacity, dopamine release and baseline synaptic dopamine concentrations in individuals with psychotic disorder [41]. If migrant status is a risk factor for psychosis, one could hypothesize that it is associated with dopamine function.

Egerton et al. [42"'] report on two complementary Canadian and UK-based PET imaging studies among three different clinical groups of individuals, one at clinical high risk (CHR) for psychosis, one with schizophrenia and one group consisting of healthy controls. The Canadian researchers examined dopamine release during exposure to the Montreal Imaging Stress Task (MIST). The MIST is a validated laboratory task during which participants receive negative feedback following an arithmetic task. As hypothesized, they found an elevated striatal dopamine release in response to MIST-induced stress in immigrants compared with nonmigrant Canadians across clinical groups. The purpose of the UK-study was to measure striatal dopamine synthesis capacity. The researchers used data on healthy controls and CHR patients and compared migrants with nonmigrants. The results showed that the striatal dopamine synthesis capacity was elevated in migrants, independent of clinical status. The authors conclude that dopamine function may be influenced by social stress [42"'].

Akdeniz et al. [43] investigated structural alterations of the perigenual anterior cingulate cortex (pACC) in healthy participants $(n=124)$, native Germans and second-generation migrants, because previous studies had revealed functional changes in this brain area in second-generation migrants [44]. The results showed a significant reduction in pACC grey matter volume in migrant males in relation to German males, although there was no such reduction in female migrants [43].

Lastly, an examination of polygenic risk scores reported that these discriminated between cases and controls of European ancestry, but much less so between those of African ancestry (9.4 versus $1.1 \%$ of the variance explained) [45]. A differential genetic architecture or environmental exposure are possible explanations.

Although epidemiological findings on migrants provide indirect evidence for social stress in the aetiology of psychosis, it remains unclear, however, exactly which elements of the social environment lead to psychotic symptoms. Using experimental paradigms, such as Virtual Reality experiments, which try to mimic real-life situations, one can test 
stress sensitivity in a controlled social environment. Veling et al. [46] validated this paradigm by demonstrating that psychosis liability was associated with paranoid thoughts and subjective distress in response to environmental stressors, specifically population density and hostility. Yet, an ethnic density effect, as operationalized by increased paranoia and subjective distress in a Virtual Reality environment with low own-group ethnic density, was not observed [46]. Another Virtual Reality study found a positive correlation between reported ethnic discrimination and paranoid persecutory ideation, but this was not observed in the Virtual Reality environment [47].

An alternative paradigm that has been developed for testing social stress sensitivity among members of ethnic minority and migrant groups is the Digital Social Peer Evaluation Experiment (digi-SPEE) [48], during which the individual is exposed to identitybased rejection. Contrary to expectation, Gevonden et al. [49] observed a blunted response to rejection in Moroccan-Dutch men. Unconscious denial of defeat and a tendency to keep up appearances have been hypothesized to account for these findings [50]. Why this defence mechanism of denial would apply to individuals with a different ethnic background and not to other defeated groups, such as individuals with a history of abuse or a hearing impairment, is, as yet, unclear.

\section{CONCLUSION}

Although some researchers emphasize the potential influence of diagnostic and sampling bias in migrant studies, the evidence generally supports the idea that certain migrant and ethnic minority groups are at an increased risk for NAPD. In fact, outcome studies from the UK show that psychosis in immigrants is not characterized by a benign course of illness. For the search of the true exposure that drives the higher incidence, it is important to note that the risk increase extends to other marginalized populations than international migrants. This seems to suggest that migration or ethnic minority status is rather a proxy for an inferior social position. Lastly, elevated dopamine in the striatal regions among immigrants could operate as an underlying neurobiological mechanism associated with psychosis susceptibility.

\section{Acknowledgements}

None.

\section{Financial support and sponsorship}

None.

\section{Conflicts of interest}

None.

\section{REFERENCES AND RECOMIMENDED}

\section{READING}

Papers of particular interest, published within the annual period of review, have been highlighted as:

- of special interest

-1. of outstanding interest

1. Bourque F, van der Ven E, Malla A. A meta-analysis of the risk for psychotic disorders among first-and second-generation immigrants. Psychol Med 2011; 41:897-910.

2. Bresnahan $M$, March $D$, Susser $E$. Race and risk of schizophrenia in a US birth cohort: findings and future directions. Am J Epidemiol 2007; 165: S139-S1139.

3. Hogerzeil SJ, van Hemert AM, Veling W, Hoek HW. Incidence of schizo-

- phrenia among migrants in the Netherlands: a direct comparison of first contact longitudinal register approaches. Soc Psychiatry Psychiatr Epidemiol 2017; 52:147-154.

A study drawing attention to the consequences of sampling bias in first-contact studies for the relative risk of schizophrenia among immigrants.

4. Hogerzeil SJ, Van Hemert AM, Rosendaal FR, et al. Direct comparison of firstcontact versus longitudinal register-based case finding in the same population: early evidence that the incidence of schizophrenia may be three times higher than commonly reported. Psychol Med 2014; 44:3481-3490.

5. Cantor-Graae E, Pedersen C. Full spectrum of psychiatric disorders related to foreign migration: a Danish population-based cohort study. JAMA Psychiatry 2013; 70:427-435.

6. Selten J-P, Slaets JPJ, Kahn RS. Schizophrenia in Surinamese and Dutch Antillean immigrants to The Netherlands: evidence of an increased incidence. Psychol Med 1997; 27:807-811.

7. Leão TS, Sundquist J, Frank G, et al. Incidence of schizophrenia or other psychoses in first- and second-generation immigrants: a national cohort study. J Nerv Ment Dis 2006; 194:27-33.

8. Denzel AD, van Esch AYM, Harte JM, Scherder EJA. Ethnic variations in psychotic disorders in the criminal justice system: a systematic review. Aggress Violent Behav 2016; 29:20-29.

9. Zandi T, Havenaar JM, Laan W, et al. Effects of a culturally sensitive assessment on symptom profiles in native Dutch and Moroccan patients with a first psychosis referral. Transcult Psychiatry 2016; 53:45-59.

10. Andreasen NC, Flaum M, Arndt S. The Comprehensive Assessment of Symptoms and History (CASH): an instrument for assessing diagnosis and psychopathology. Arch Gen Psychiatry 1992; 49:615-623.

11. Zandi $T$, Havenaar JM, Limburg-Okken AG, et al. The need for culture sensitive diagnostic procedures. Soc Psychiatry Psychiatr Epidemiol 2008; 43: 244-250.

12. Termorshuizen F, Selten JP, Heerdink ER. Dispensing of psychotropic med-

- ication among 400,000 immigrants in The Netherlands. Soc Psychiatry Psychiatr Epidemiol 2017; 52:963-977.

An incident dispensing of antipsychotics is increased among the Turkish and Moroccan-Dutch, but not among Surinamese and Antillean-Dutch individuals, even though a higher incidence of psychotic disorders has been reported for the latter two groups.

13. Veling $W$, Selten JP, Veen $N$, et al. Incidence of schizophrenia among ethnic minorities in the Netherlands: a four-year first-contact study. Schizophr Res 2006; 86:189-193.

14. Selten JP, Laan W, Kupka R, et al. Risk of psychiatric treatment for mood disorders and psychotic disorders among migrants and Dutch nationals in Utrecht, The Netherlands. Soc Psychiatry Psychiatr Epidemiol 2012; 47: 271-278.

15. Pignon B, Schürhoff $F$, Szöke $A$, et al. Sociodemographic and clinical correlates of psychotic symptoms in the general population: findings from the MHGP survey. Schizophr Res 2017. [Epub ahead of print]

16. Van Os J, Linscott RJ, Myin-Germeys I, et al. A systematic review and metaanalysis of the psychosis continuum: evidence for a psychosis pronenesspersistence-impairment model of psychotic disorder. Psychol Med 2009; 39:179-195.

17. Littlewood R, Lipsedge M. Acute psychotic reactions in Caribbean-born patients. Psychol Med 1981; 11:303-318.

18. Morgan $C$, Fearon $P$, Lappin J, et al. Ethnicity and long-term course and

1. outcome of psychotic disorders in a UK sample: the ÆESOP-10 study. Br J Psychiatry 2017; 211:88-94.

Ten-year outcome of the seminal AESOP study showing that the higher incidence in black, ethnic minority groups in the UK extends to worse long-term outcome in multiple domains of functioning.

19. Ajnakina $O$, Lally J, Di Forti $M$, et al. Patterns of illness and care over the 5 years following onset of psychosis in different ethnic groups; the GAP-5 study. Soc Psychiatry Psychiatr Epidemiol 2017; 52:1101-1111. 
20. Mindlis I, Boffetta P. Mood disorders in first- and second-generation immigrants: systematic review and meta-analysis. $\mathrm{Br} J$ Psychiatry 2017; 210:182-189.

21. Pignon $B$, Geoffroy PA, Thomas $P$, et al. Prevalence and clinical severity of mood disorders among first-, second- and third-generation migrants. J Affect Disord 2017; 210:174-180.

22. Lloyd T, Kennedy N, Fearon $P$, et al. Incidence of bipolar affective disorder in three UK cities. Br J Psychiatry 2005; 186:126-131.

23. Coid JW, Kirkbride JB, Barker D, et al. Raised incidence rates of all psychoses among migrant groups. Arch Gen Psychiatry 2008; 65:1250-1258.

24. Kirkbride JB, Errazuriz A, Croudace TJ, et al. Incidence of schizophrenia and other psychoses in England, 1950-2009: a systematic review and metaanalyses. PLoS One 7; 2012:e31660.

25. Mustelin L, Hedman AM, Thornton LM, et al. Risk of eating disorders in immigrant populations. Acta Psychiatr Scand 2017; 136:156-165.

26. Modabbernia $A$, Velthorst $E$, Reichenberg $A$. Environmental risk factors for autism: an evidence-based review of systematic reviews and meta-analyses. Mol Autism 2017; 8:13.

27. Lorant V, Rojas VS, Bécares $\mathrm{L}$, et al. A social network analysis of substance use among immigrant adolescents in six European cities. Soc Sci Med 2016; 169:58-65.

28. Barnes DM, Bates LM. Do racial patterns in psychological distress shed light

- on the Black-White depression paradox? A systematic review. Soc Psychiatry Psychiatr Epidemiol 2017; 52:913-928.

Despite their lower socioeconomic status and higher exposure to social distress, this review summarizes consistent findings of paradoxically low prevalence rates of major depression disorder in African-Americans.

29. Tortelli A, Errazuriz A, Croudace $T$, et al. Schizophrenia and other psychotic disorders in Caribbean-born migrants and their descendants in England: systematic review and meta-analysis of incidence rates, 1950-2013. Soc Psychiatry Psychiatr Epidemiol 2015; 50:1039-1055.

30. Cantor-Graae E, Selten JP. Schizophrenia and migration: a meta-analysis and review. Am J Psychiatry 2005; 162:12-24.

31. Veling W, Susser E, Van Os J, et al. Ethnic density of neighborhoods and incidence of psychotic disorders among immigrants. Am J Psychiatry 2008; 165:66-73.

32. Hollander $A C, D a l ~ H$, Lewis $G$, et al. Refugee migration and risk of schizo-

-1. phrenia and other nonaffective psychoses: cohort study of 1.3 million people in Sweden. BMJ 2016; 352:i1030.

A study suggesting that compared with the native Swedish-born population, the incidence of NAPD is higher in refugees than in nonrefugee migrants from similar regions of origin.

33. Kirkbride JB, Hameed $\mathrm{Y}$, loannidis $\mathrm{K}$, et al. Ethnic minority status, age-at-

immigration and psychosis risk in rural environments: evidence from the SEPEA study. Schizophr Bull 2017; 43:1251-1261.

A large incidence study showing that the risk pattern of NAPD among immigrants in

rural Britain resembles findings from urban environments.

34. Fearon $P$, Kirkbride J, Morgan $C$, Dazzan P. Incidence of schizophrenia and other psychoses in ethnic minority groups: results from the MRC AESOP Study. Psychological Med 2006; 36:1541-1550.

35. van der Ven $\mathrm{E}$, Veling $\mathrm{W}$, Tortelli $\mathrm{A}$, et al. Evidence of an excessive gender gap in the risk of psychotic disorder among North African immigrants in Europe: a systematic review and meta-analysis. Soc Psychiatry Psychiatr Epidemiol $2016 ; 51: 1603-1613$
36. Tarricone I, Boydell J, Kokona A, et al. Risk of psychosis and internal migration: results from the Bologna First Episode Psychosis study. Schizophr Res 2016; 173:90-93.

Here, the authors report that compared with Italians born in Emiglia Romagna, the risk for psychosis is not only increased in external but also in internal migrants, predominantly from Southern Italy. Of note, Southern Italians constitute a discrimated group in Northern Italy.

37. Tapsell R, Hallett C, Mellsop G. The rate of mental health service use in New

Zealand as analysed by ethnicity. Australas Psychiatry 2017. [Epub ahead of print]

This is the first study to provide evidence for higher rates of schizophrenia in the Maori in New Zealand, an ethnic minority group without migration history.

38. Khawar M. North versus south-an examination of regional comparative development in Italy and Brazil. In: The geography of underdevelopment. New York: Palgrave Macmillan; 2017. pp. 25-34.

39. Schofield $P$, Thygesen M, Das-Munshi J, et al. Ethnic density, urbanicity and

- psychosis risk for migrant groups: a population cohort study. Schizophr Res 2017; 190:82-87.

Contribution from Denmark supporting a prospective association between low own-group ethnic density at 15 years of age and risk of NAPD in adult life. The findings provide evidence that the ethnic density effect is not a result of differential mobility during the prodromal phase.

40. Das-Munshi J, Chang C-K, Dutta R, et al. Ethnicity and excess mortality in severe mental illness: a cohort study. Lancet Psychiatry 2017; 4:389-399.

41. Howes OD, Murray RM. Schizophrenia: an integrated sociodevelopmentalcognitive model. Lancet 2014; 383:1677-1687.

42. Egerton $A$, Howes OD, Houle $S$, et al. Elevated striatal dopamine function in

n- immigrants and their children: a risk mechanism for psychosis. Schizophr Bull 2017; 43:293-301.

First evidence that the increased risk for NAPD in immigrants may be mediated by elevated dopamine in striatal regions in the brain.

43. Akdeniz $C$, Schäfer $A$, Streit $F$, et al. Sex-dependent association of perigenual anterior cingulate cortex volume and migration background, an environmental risk factor for schizophrenia. Schizophr Bull 2017; 43:925-934.

44. Akdeniz $\mathrm{C}$, Tost $\mathrm{H}$, Streit $\mathrm{F}$, et al. Neuroimaging evidence for a role of neural social stress processing in ethnic minority-associated environmental risk. JAMA Psychiatry 2014; 71:672-680.

45. Vassos E, Forti MDi, Coleman J, et al. An examination of polygenic score risk prediction in individuals with first-episode psychosis. Biol Psychiatry 2017; $81: 470-477$.

46. Veling $\mathrm{W}$, Pot-Kolder $\mathrm{R}$, Counotte J, et al. Environmental social stress, paranoia and psychosis liability: a virtual reality study. Schizophr Bull 2016; 42:1363-1371.

47. Shaikh M, Ellett L, Dutt A, et al. Perceived ethnic discrimination and persecutory paranoia in individuals at ultra-high risk for psychosis. Psychiatry Res 2016; 241:309-314.

48. Menne-Lothmann C, Decoster J, van Winkel R, et al. Psychological and biological validation of a novel Digital Social Peer Evaluation Experiment (digi-SPEE). Noro Psikiyatr Ars 2017; 54:3-10.

49. Gevonden M, Myin-Germeys I, Wichers $M$, et al. Reactivity to social stress in ethnic minority men. Psychiatry Res 2016; 246:629-636.

50. Selten JP, van Os J, Cantor-Graae E. The social defeat hypothesis of schizophrenia: issues of measurement and reverse causality. World Psychiatry $2016 ; 15: 294-295$. 